\title{
ALIMENTAÇÃO: ENTRE A MEMÓRIA, O PATRIMÓNIO E A IDENTIDADE
}

\section{FOOD: AMID MEMORY, HERITAGE AND IDENTITY}

\author{
Ana Piedade \\ alavado@ipbeja.pt; \\ af.piedade67@gmail.com
}

Departamento de Educação, Ciências Sociais e do Comportamento Instituto Politécnico de Beja (IPBeja); Lab-At/IPBeja; CRIA (Centros em Rede para a Investigação em Antropologia) - Polo UNL-FCSH.

Professora Adjunta.

ORCID: https://orcid.org/0000-0002-6203-9424

\section{(c) 190(}

Esta obra está licenciada sob uma licença Creative Commons Attribution-NonCommercial-ShareAlike 4.0 International License.

\section{RESUMO}

A alimentação é uma questão importante do Património Cultural Imaterial. A sua dimensão de saber e saber-fazer, transmitidos de geração em geração, alicerçados principalmente nas tradições orais e centrados nas práticas culturais e sociais, conferem poder, identidade e continuidade temporal às comunidades. Em 2000, o Conselho de Ministros de Portugal emanou uma resolução que visa estudar e preservar "o receituário tradicional português, assente, designadamente, em matérias-primas de fauna e flora utilizadas ao nível nacional, regional ou local, bem como em produtos agroalimentares produzidos em Portugal, e que, pelas suas características próprias, revele interesse do ponto de vista, histórico, etnográfico, social ou técnico, evidenciando valores de memória, antiguidade, autenticidade, singularidade ou exemplaridade" (RCM No $96,2000)$. Assim, a lei estabelece diversas regras com o objetivo de preservar e desenvolver a promoção de uma gastronomia nacional como elemento representativo do património cultural português. O processo de definição das bases do patrimônio é uma construção das elites e possui uma dimensão política e ideológica que não pode ser escamoteada e que determina o que deve ser valorizado, num determinado momento temporal e contexto político. Neste sentido, os territórios são quebra-cabeças políticos que refletem identidades desejadas e transitórias, ao mesmo tempo cristalizadas e transformadas no tempo. O património é dotado de uma dimensão política determinante na identidade gastronómica e alimentar, no que se refere ao local, regional e global. Já as instituições de governança local buscam estimular os territórios sob a sua influência, por meio da aceitação e /ou promoção de ações de marketing e "rótulos" geradores de marcas locais que, muitas vezes, reforçam símbolos de identidade ou os (re) inventam. Os processos de turistificação 
dos lugares históricos e centros das cidades estão pouco distantes dessas atitudes e, tal como nestes casos, a intenção inicial de preservação dos sistemas alimentares, pode resultar na adulteração dos pratos servidos.

Palavras-chave: alimentação; processos de patrimonialização; identidade; memória social.

\section{ABSTRACT}

Food is an important issue of Intangible Cultural Heritage. Its dimension of knowledge and know-how is transmitted from generation to generation, based mainly on oral traditions and centered on cultural and social practices, giving a sense of power, identity and temporary continuity for communities. In 2000, the Portuguese Council of Ministers come out with a resolution whose aim was to study and preserve "the recipes of Portuguese national traditional cuisine, particularly the cuisine based on autochthonous fauna and flora as well as local, regional and national products. Also, those products manufactured in Portugal and considered of interest from cultural, historical, ethnographical, social or technical points of view, bearing values of memory, ancestry, authenticity, singularity or symbolic, should be cherished" (RCM No 96, 2000). Thus, the law establishes several rules in order to preserve and develop the promotion of a national cuisine as a representative aspect of the Portuguese cultural heritage. The process of defining the bases of heritage are an elite construct and a political perspective of what shall be valued in a certain moment in time; and in a certain political context. So, territories are political puzzles that show desired and transitional identities, at once crystalized and transformed in time. Heritage is supplied with a political dimension that is determinant in the gastronomic and alimentary identity, concerning the local, regional and global. Local governance institutions on the other hand, try to encourage the territories under its influence, by the acceptance and /or promoting marketing actions and labels generating local brands that often reinforce identity symbols or (re)invent them. The processes of transforming historical places and city centers in tourist attractions are hardly far from these attitudes and, as a consequence of these acts, the initial intention of preservation turns into degradation.

Keywords: food; heritage processes; identity; social memory.

\section{INTRODUÇÃO}

Abordar-se-ão, no presente texto, alguns aspetos relativos aos conceitos de património; às políticas de construção dos processos de patrimonialização e da ideia de património; à dimensão política e legislativa enquadradora do que se considera, em determinado contexto, como património e, ainda, ao modo como a comida e a alimentação têm vindo a constituir-se como um importante aspeto do património cultural ima- 
terial, com valor também económico e turístico. Neste sentido, interessa-nos compreender vários aspetos desta interação. $\mathrm{O}$ primeiro aspeto respeita à forma como se processa a interação entre a comida e o património, isto é, de que forma a alimentação está a ser apropriada como património cultural imaterial; o segundo aspeto diz respeito à dimensão política do património e, portanto, do património alimentar como construção política e de elite; o terceiro e último aspeto, aborda o surgimento de processos de turistificação nos territórios, a partir de práticas de consumo alimentar, com o apoio das instituições de governança local (semanas culinárias, concursos de especialidades gastronómicas, festivais, congressos...). O território trabalhado, mais do que um local físico, foi um conjunto de pessoas, portadoras de práticas e representações, geograficamente situado nos concelhos de Beja e Serpa, no Baixo Alentejo; nos concelhos do Barreiro e Moita, na área metropolitana de Lisboa e, por fim, no centro da cidade de Lisboa (Ruas Áurea ou do Ouro, da Prata, Augusta, dos Fanqueiros, de Santa Justa, da Conceição, de S. Julião...). Cada uma destas pessoas constitui um terreno de pesquisa e contribui com um conjunto de conhecimentos e experiências diversas no que concerne à alimentação e ao cruzamento de lugares, tanto em Portugal como no estrangeiro, como se verá em seguida.

\section{ASPETOS METODOLÓGICOS}

Em Beja e em Serpa, entrevistaram-se e recolheram-se narrativas de vida de pessoas que consumiram e consomem a dita comida tradicional (algumas das quais com experiência de emigração, em algum momento da sua vida); na área metropolitana de Lisboa, idem. Neste território, foram ainda recolhidos testemunhos de quem nunca contactou diretamente com este tipo de comida que designaremos "de pobreza", como é o caso de descendentes de migrantes do Baixo Alentejo, já nascidos aqui. Em Lisboa, em pleno centro turístico (e turistificado), fez-se observação direta (dos pratos consumidos por turistas estrangeiros) e recolheram-se testemunhos de funcionários de restaurantes.

A abordagem metodológica é, portanto, ancorada em trabalho de campo, realizado numa primeira fase, nas cidades de Serpa e Beja mas também na periferia de Lisboa, mais concretamente nos concelhos do Barreiro e Moita.

No caso dos concelhos de Beja e Serpa, procedeu-se à análise de ementas de restaurantes que reivindicam servir "comida tradicional" e recolheram-se depoimentos de funcionários (cozinheiros e empregados de mesa), proprietários e clientes. Foram, ainda, recolhidos depoimentos e histórias de vida de naturais dos concelhos de Beja e Serpa, migrantes, idosos e há muitos anos residentes em localidades dos concelhos do Barreiro e Moita e descendentes destes. O intuito é compreender as diferenças entre a comida tradicional confecionada em casa, em tempos de pobreza e, mais tarde, de menos escassez ou mesmo de abundância, e 
a que se serve nos restaurantes. É inevitável relacionar os fenómenos de patrimonialização da comida alentejana com a transformação de comida de pobres em comida de elites.

Numa segunda fase, e desde que Lisboa tem vindo a ganhar dimensão em termos de atração turística, também a capital se constituiu como terreno de pesquisa. $\mathrm{O}$ trabalho de campo levado a cabo em Lisboa foi pontual e resultou do confronto da investigadora com pratos servidos a turistas que, supostamente seriam tradicionais, mas cuja gramática de sabores rompia com a tradição e a "lógica" culinária. Neste contexto, foram sendo observadas as mesas, maioritariamente de esplanadas, no centro histórico e emblemático da cidade. É sobretudo aqui que se identificam alterações nos pratos que chegam à mesa de turistas estrangeiros, alegadamente para satisfazer o gosto ou as preferências por eles manifestadas, relativamente aos pratos tradicionais que são apresentados nas ementas. Esta dimensão do trabalho apelou, sobretudo, à observação direta e a conversas exploratórias com funcionários dos restaurantes onde se detetaram as situações reportadas.

O número de informantes privados dos concelhos de Beja e Serpa, ascende, neste momento, a trinta. Encontram-se neste grupo, homens e mulheres, com idades compreendidas entre os 53 e os 98 anos. As suas profissões são variadas, destacando-se duas mulheres com idades superiores a 90 anos, antigas cozinheiras em casas nobres e das elites, dos concelhos referidos.

O grupo de profissionais estudados no contexto destes concelhos, engloba proprietários e funcionários de cafés (que servem petiscos), tascas e restaurantes e o seu número ascende a onze pessoas. Foram observados de modo mais aprofundado, cinco restaurantes (dois em Serpa e três em Beja); um café que serve petiscos e uma tasca (em Serpa). Foram igualmente analisadas as ementas (fixas e móveis) de mais sete restaurantes que no concelho de Beja, referem servir "comida típica" e/ ou "tradicional" alentejana.

$\mathrm{Na}$ área metropolitana de Lisboa, nomeadamente nos concelhos do Barreiro e da Moita, entrevistaram-se e recolheram-se narrativas de vida de sete homens e mulheres que migraram do distrito de Beja e de nove dos seus descendentes.

Os dados obtidos no trabalho de campo são cruzados com fontes secundárias, nomeadamente livros de receitas, outras recolhas de campo e obras literárias que descrevem a "alimentação da pobreza" no Alentejo, em diferentes momentos. Reportamo-nos, por exemplo, a autores como Fialho de Almeida (1857-1911) e Manuel da Fonseca (1911-1993). Incontornável é também a figura de Alfredo Saramago (1938 -2020), gastrónomo, historiador e antropólogo, investigador da história e antropologia da alimentação e de Maria Antónia Goes (1943), igualmente investigadora e autora de várias obras sobre a cozinha alentejana. Também a recente Carta Gastronómica do Alentejo Monumenta 
Transtaganae, realizada sob a direção científica do antropólogo Paulo Lima, constitui uma importante ferramenta de trabalho no contexto da presente investigação.

Recolheram-se junto dos informantes (migrantes e dos concelhos de Beja e Serpa), com frequência numa muito prazerosa observação participante, um acervo generoso de pratos que eram consumidos nas suas casas e nas casas dos seus pais e avós. Destes pratos daremos conta mais adiante.

\section{ALIMENTOS COMO PATRIMÓNIO CULTURAL IMATERIAL}

A ideia de património e memória, como conceitos interrelacionados, tem grande importância em nossos dias. O mundo contemporâneo enfrenta desafios económicos, políticos, sociais e humanitários que influenciam quer a forma como as pessoas lidam com seu passado, quer o modo como moldam suas identidades e ideias de futuro. A ideia do "património em perigo" e que urge salvar, continua a ter uma importância incontornável da nova narrativa do património, veiculada pela UNESCO". Os processos de "globalização hegemónicos", a "acelerada mudança social" e as sucessivas crises financeiras, todos reais, são evocados a propósito deste sentido de urgência:

Os processos de globalização e transformação social, ao mesmo tempo que criam as condições para um renovado diálogo entre as comunidades também dão origem, como o faz o fenómeno da intolerância, a graves ameaças de deterioração, desaparecimento e destruição do Património Cultural Imaterial, em particular devido à falta de recursos para a salvaguarda de tal património (UNESCO, 2003, Preâmbulo).

Olhar para o presente e para o futuro, implica, portanto, lembrar e reconfigurar o passado. Assim, conceptualizar a comida como um símbolo de herança e como património, permite que tanto sociedades como indivíduos aumentem a sua consciência cultural, proclamando livremente suas identidades e aspirando a uma visibilidade crescente dos seus territórios, e das suas experiências de vida. Ao mesmo tempo, refletem e sucesso económico e social que foram atingindo, e de que, em última instância, resultam processos de memória e (tentativas) de esquecimento e/ou reconfigurações das comidas do passado, criando narrativas alternativas.

A comida e a culinária são questões importantes no que concerne ao Património Cultural Imaterial. A sua dimensão de conhecimento e saber-fazer, transmitida de geração em geração, baseada principalmente em tradições orais e centrada em práticas culturais e sociais, dá uma sensação de poder, identidade e continuidade temporal às comunidades. Assim, pensar em categorizações do património alimentar - como local, tradicional, autêntico e "étnico" (CANESQUI; GARCIA, 2005) emerge da nostalgia de espaços culturais e sociais onde se espera que os consumidores de alimentos experienciem livremente, no seu contexto 
identitário, sabores, odores, técnicas e segredos ou truques de família, que conferem ao prato cozinhado o sabor "autêntico" e esperado (apoiados por culturas culinárias com as quais possam ser identificados e identificar-se). A comida tradicional é, portanto, segura e permite construir identidades, reconhecer alteridades e conhecer a cultura do indivíduo que lhe pertence, e a cultura dos outros.

O sentido multidimensional de grupos e circunstâncias de alimentação, culinária e consumo é obviamente cultural e contextual, permitindo a coexistência entre processos de patrimonialização, manutenção, inovação e reinvenção da tradição. De facto, é indispensável que as medidas normativas que têm como objetivo a preservação das práticas alimentares e culinárias, não obriguem à cristalização das práticas, nem impeçam o estabelecimento, para usar as palavras de Lowenthal, de novas "conexões criativas com o passado" (LOWENTHAL, 1998a, p. 364). Será essa a única forma de patrimonializar o real, já que, sem a participação e adesão das comunidades, afinal as detentoras dos conhecimentos e das práticas culturais, todos os processos de patrimonialização serão transitórios ou impostos.

No que concerne à alimentação e práticas culinárias, os processos de patrimonialização apenas podem potenciar-se através do estabelecimento e do reforço da interação entre o tradicional e o contemporâneo, visível na transformação sofrida, por exemplo, entre os rácios de proteína e pão, dos pratos de açordas e migas alentejanas, servidos nos restaurantes. Tradicionalmente, exceto nas casas ricas, a porção de carne ou peixe que entrava na confeção de um prato era mínima, configurando uma comida de pobres, que se servia das ervas aromáticas e dos alhos para conferir sabor e aroma aos pratos. Hoje, a restauração não pode servir a comida de pobreza, sob pena de a comida tradicional alentejana não ser vendida aos turistas, nem aos locais. Assim, ela reconfigura-se para se manter - continua tradicional nos ingredientes e modos de cozinhar, mas torna-se comida de elite, aumentando a quantidade de peixe, carne e gordura relativamente ao pão, ao grão, ao feijão... Mais cara e mais enriquecida, mais proteica e menos "dieta mediterrânica" (validada como património cultural imaterial da humanidade pela UNESCO, e enaltecida), é, por isso mesmo, vendável e vendida, consumida pelas elites e por aqueles que, tendo-a consumido durante toda a vida, se reinventam em novas narrativas. Alguns outros, que também a consumiram, continuam a recusá-la, recusando, simbolicamente, uma vida, uma identidade e uma pertença (como, por exemplo, se verifica no caso de alguns migrantes para a área metropolitana de Lisboa). Ouçamo-los:

Os meus filhos pedem... ó mãe... a mãe podia fazer umas migas! E eu, p’ra mim: tá bem, deixa. Soubesses tu que isso era o pão que o diabo amassou... migas... é bom p’ra vocês que querem o pão encharcado no pingo da carne. Mas a gente 'nã tinha carne... pois, as minhas [migas] não eram como essas. E agora querem a banha tingida... a gente se apa- 
nhasse manteiga... eu não como já nada disso! Agora, felizmente, a gente pode mais, não é? As reformas são 'pocachinhas' mas sempre é menos mal. Ai! Havia muita fome. Nem me quero lembrar... as mulheres com um rancho de moços todos de volta a pedir pão... e a gente, às nossas mães... passou-se muito [...] (G.S., 2018).

Outros, ainda, da "geração dos tempos de fartura, que não sabe o que é sofrer nem dividir uma sardinha por três” (M.V.C., 2012), descendentes dessa primeira geração dos migrantes do Alentejo pobre, reivindicam a comida tradicional com a qual não cresceram. Consomem-na, confecionam-na e, em alguns casos, levam-na mundo fora, na nova diáspora dos portugueses altamente qualificados, mas ainda emigrantes:

Já andei por muito lado, sim. Ainda estou emigrado... agora estou na Dinamarca, mas vou para França. Faço eu os petiscos. Gosto muito de pezinhos de coentrada... e faço bem! Mas não aprendi com a minha mãe nem com as minhas tias daqui [Barreiro]. Elas recusam alguma comida típica, sabe... adaptaram-se bem à comida daqui, com mais peixe. É mais saudável [...] (C.G., 2019).

Esta geração, em alguns casos, como neste que aqui se plasmou, branqueia a pobreza e recusa assumir o estatuto social da família, do qual a comida (ou a recusa da comida) é testemunho.

Sendo inútil a tentativa salvar todo e qualquer vestígio do passado - e seria, certamente, disparate pretendê-lo, até porque as populações e comunidades recusam, frequentemente, a manutenção de fatores que lhes recordam maus momentos, dificuldades e estagnação económica e social observada durante gerações - o esforço legislativo, político e também científico, deverá orientar-se no sentido de trabalhar e reconfigurar as heranças culturais. Como refere um dos informantes residentes no concelho de Serpa, relativamente à sua vida em criança:

[...] o meu pai não era das pessoas que ganhavam pior, éramos apenas três irmãos e, mesmo assim, comia-se carne a sério, uma vez por semana. Comia-se porco ou carneiro. De resto, a alimentação era muito pobre em proteína. O peixe era muito frequentemente bacalhau [...] sim, o bacalhau era barato, bem como a sardinha. Mas havia muita gente a comer migas de assobio! Sabe o que era?! Migas apenas confecionadas com molho de toucinho e uns bocadinhos minúsculos de carne ou toucinho, e poucos!... por isso, quem apanhava algum, assobiava! As coisas estão muito diferentes agora... e em casa, claro, as pessoas também já não comem assim, consomem muito mais carne e peixe (J.O., 2016).

Emerge, portanto, a dimensão patrimonial de transformação e reapropriação da tradição. Assim, a lei estabelece diversas regras para preservar e desenvolver a promoção de uma culinária nacional como aspeto representativo do património cultural português. A RCM no 96 de 2000 cujo objetivo é estudar e preservar

as receitas da culinária tradicional portuguesa, particularmente a culinária baseada na fauna e flora autóctones, bem como produtos locais, 
regionais e nacionais. Também aqueles produtos fabricados em Portugal e considerados de interesse do ponto de vista cultural, histórico, etnográfico, social ou técnico, cuidando de valores de memória, antigos, autenticidade, singularidade ou simbólico, devem ser valorizados (RCM no 96, 2000).

Em diferentes contextos, portanto, tanto internacionais (UNESCO), como nacionais e regionais, a política patrimonial está a incentivar a revitalização e a promoção de produtos alimentares particulares e "tradicionais" com diferentes objetivos, entre os quais se destacam o reconhecimento cultural e a exploração do mercado. Em Portugal, essa estratégia também foi incentivada. Como refere a Resolução do Conselho de Ministros (RCM no 96, 2000), já referida e à qual voltaremos,

É hoje inquestionável que a identidade cultural dos povos, a par de bens corpóreos que testemunham o respetivo percurso civilizacional, integra ainda um vasto património intangível que, ao longo do tempo, vai revelando a sua particular visão da realidade. Entre estes modos de expressão cultural, muitas vezes sem suporte físico e mais vulneráveis do ponto de vista da respetiva preservação, mas, contudo, relevantes pelo contributo para a caracterização de certos aspetos de uma nação ou das partes que a compõem, figuram, entre outras, as artes culinárias. Entendida como o fruto de saberes tradicionais que atestam a própria evolução histórica e social do povo português, a gastronomia nacional integra pois o património intangível que cumpre salvaguardar e promover [...] (RCM no 96, 2000).

Estamos, portanto, como nos documentos da UNESCO três anos depois, a pensar em salvaguardar.

A dimensão do património alimentar foi, em grande medida, e durante bastante tempo, ignorada pelas políticas europeias e globais dominantes, que lidam com alimentos e desenvolvimento sustentável. Assim, é relativamente recente o impacto dos valores culturais e sociais atribuídos à alimentação, bem como a noção da importância que efetivamente a comida tem, enquanto forma de património cultural, do ponto de vista político. Contudo, nos últimos anos, em Portugal, já há duas décadas, tem surgido um certo discurso crítico, que questiona o modo como se desenvolvem os processos de patrimonialização e o envolvimento das comunidades, nas dinâmicas que os conduzem. Coloca-se uma nova ênfase na inter-relação entre elementos materiais e imateriais, na construção e na promoção da memória dos grupos e das memórias sociais e reflete-se acerca da promoção do património imaterial por parte de organizações internacionais.

Neste caso, considerando a estreita relação entre património e identidade, a identidade de um grupo/sociedade é sempre um processo seletivo e fragmentado (RODRIGUES, s.d.), em cujo processo de construção, afirmação e reconstrução, a comida, como outros elementos culturais, podem transformar-se (transformam-se) em "marcadores identitários, 
apropriados e usados pelo grupo como signos diacríticos, símbolos de uma identidade reivindicada" (DAMATTA, 1987, p. 56).

De algum modo, o Estado em Portugal, a UNESCO, mas também o ICOM, legitimam politicamente, durante este tempo, os sistemas alimentares, bem como contextos de consumo e formas de cozinhar. Convoquemos de novo a RCM de 2000:

Assim: Nos termos da alínea g) do artigo $199^{\circ}$ da Constituição, o Conselho de Ministros resolve: 1 - Intensificar as medidas de preservação, valorização e divulgação da gastronomia nacional enquanto valor integrante do património cultural português. $2-[\ldots]$ entende-se por gastronomia nacional o receituário tradicional português, assente, designadamente, em matérias-primas de fauna e flora utilizadas ao nível nacional, regional ou local, bem como em produtos agroalimentares produzidos em Portugal, e que, pelas suas características próprias, revele interesse do ponto de vista, histórico, etnográfico, social ou técnico, evidenciando valores de memória, antiguidade, autenticidade, singularidade ou exemplaridade. 3 - As medidas referidas no ${ }^{\circ} 1$ compreendem, nomeadamente: a) O levantamento do receituário tradicional português, em toda a sua diversidade, evidenciando-se os aspetos que o singularizam; b) A criação de uma base de dados de receitas e produtos tradicionais portugueses; c) A identificação dos requisitos que permitam a certificação de receitas e produtos tradicionais portugueses; [...] (RCM no 96, 2000).

Ao evidenciar os valores da memória, esta RCM remete-nos para Halbwachs, e para as questões dos quadros sociais da memória. Afirma o autor, que é no contexto da sociedade que, normalmente, se adquirem as memórias (HALBWACHS, 1992, p. 38). É também no contexto social, que se organizam as recordações e é possível localizar as memórias. Isto é, elas surgem contextualizadas no espaço e no tempo, sendo frequentemente partilhadas por um grupo mais ou menos alargado de indivíduos. A comida, é sabido, suscita memórias e recordações pessoais, de grupo e mais alargadas (as coletivas), por via dos sabores e dos odores. Os sentidos tornam-se simultaneamente gatilhos da memória e aspetos que se pretendem transmitir de geração em geração, (re)produzindo aquilo que cada um, mas também o grupo, considera como autêntico e suscetível de ser mantido para além (e apesar) das elites, que definem e instituem os processos de patrimonialização.

Uma vez mais, tempo e memória se articulam nos processos de replicação de práticas culturais, entre as quais, as práticas culinárias. Ao mesmo tempo, porque gerada no seio do grupo, como volta a referir Halbwachs (1992), a memória, como fenómeno social, é coletivamente construída e reproduzida ao longo do tempo e, portanto, dinâmica, mutável e seletiva. Por via do esquecimento (AUGÉ, 1994), por vezes tão importante como a memória, e que de certo modo a possibilita, permitindo-lhe ser seletiva, aproxima-se das características do património: nem todos os elementos culturais produzidos pelo grupo são passíveis 
de ser patrimonializados; nem tudo o que é importante para o grupo, se transforma em memória social. A mesma situação será válida para as memórias pessoais, pois, como uma vez mais o autor refere, a memória individual (a existir - e cremos que existe) é construída, necessariamente, a partir de um grupo. Estando ligada a um fluxo de tempo que transporta um passado vivido, constitui-se, igualmente, como memória histórica e coletiva. Permite, portanto, construção de narrativas sobre o passado, com base na recordação e reconfiguração de memórias relativas a acontecimentos/momentos marcantes na vida do grupo, da comunidade, do país, e, nestes tempos de globalização, do mundo.

A reconfiguração das narrativas por parte dos informantes, a que já nos referimos, traduzem esta memória histórica e coletiva no que concerne à comida, à culinária, aos tempos de miséria e aos de fartura. Configura, portanto, diferentes tipos de identidade e de pertença identitária, a partir da memória coletiva. A memória coletiva, que garante coesão e continuidade histórica e social do grupo, gera, neste caso, diferentes grupos que reivindicam diferentes pertenças identitárias a um espaço comum, dependendo do que é lembrado e esquecido; do que se decide valorizar. Em última instância, a memória configura ideologias de grupo.

\section{A DIMENSÃo POLÍTICA DOS PROCESSOS DE PATRIMONIALIZAÇÃO}

Politicamente, o património cultural pode ser uma força coesa ou divisiva quando explorada para fins políticos, direcionados para a hegemonia política. Os estudos patrimoniais vindo a inserir-se no âmbito de uma abordagem crítica das políticas e práticas patrimoniais é como uma complexa teia de relações de poder, sempre sujeitas a mudanças, negociações e contestações (PEIXOTO, 2002) e sem dúvida que a preservação do património é um elemento da política cultural em geral.

Não é nosso objetivo explorar as políticas públicas que enquadram os processos de patrimonialização das práticas alimentares e culinárias, mas antes refletir de forma brevíssima, acerca das posições ideológicas e políticas que permitiram chegar, na atualidade, à ideia de património imaterial como um elemento importante a preservar e estudar. Neste contexto, importa olhar os olhares dos teóricos que nos antecederam e as diferentes perspetivas que a ideia de património, em geral, convoca. Pérez (2003), diz-nos que as posturas face ao património têm sido distintas ao longo do tempo: tradicionalista ou folclorista; construtivista; patrimonialista; produtivista ou mercantilista e, ainda, participacionista. Em comum, têm subjacente uma ideologia e uma atitude política: “a retórica política utiliza o património cultural para a sua própria legitimação, representando assim a nova heráldica do poder" (PÉREZ, 2003, p. 18).

O processo de definição das bases do património é uma construção das elites e, como tal, reflete uma perspetiva política do que será 
valorizado num determinado momento no tempo e num determinado contexto político. De facto, como nos diz (PRATS, 1997), o património é um constructo social, e, como tal, uma invenção, no sentido em que é uma conceptualização da realidade. Neste sentido, constitui-se apenas como parcela da realidade, uma parte, apenas, do conjunto das ações humanas, que têm lugar num determinado período histórico (PERALTA, 2000).

Os territórios são quebra-cabeças políticos que expressam identidades desejadas e transitórias, ao mesmo tempo cristalizadas e transformadas no tempo. Ao património é conferida uma dimensão políti$\mathrm{ca}$, determinante na identidade gastronómica e alimentar, no que diz respeito às perspetivas locais, regionais e globais, na medida em que se situam entre particularidades e hegemonias.

Desde que a UNESCO adotou a Convenção para a Salvaguarda do Património Cultural Imaterial, em 2003, assistiu-se, em diferentes setores da vida pública e política, a uma crescente consciência global da importância do património imaterial. Esta entidade tem tido, ao longo do tempo, um papel fundamental no envolvimento, mobilização e valorização tanto do património, como dos profissionais ligados a esta área. De facto, este trabalho de rede que tem vindo a estabelecer e a cimentar, com diferentes organizações não governamentais e com os próprios Estados-membro, configura o que Arantes designa como construção de uma "esfera pública cultural global", que valida o património intangível como algo pertencente às comunidades, inserido nos processos culturais, representações e práticas das comunidades (ARANTES, 2006). Neste sentido, recupera algumas das ideias expressas já nos anos setenta (1971), nos encontros do $\mathrm{MINOM}^{2}$ e ainda, quando o Conselho Executivo da Organização das Nações Unidas cria a Proclamação das Obras Primas do Património Oral e Imaterial da Humanidade, a fim de: "distinguir [...] formas de expressão popular e tradicional tais como as línguas, a literatura oral, a música, a dança, os jogos, a mitologia, rituais, costumes [...]".

Em 2003 é assinada em Paris a Convenção para a Salvaguarda do Património Cultural Imaterial (CSPCI), que remete já para o respeito pela diversidade e para os direitos humanos:

[...] Entende-se por "património cultural imaterial" as práticas, representações, expressões, conhecimentos e competências - bem como os instrumentos, objetos, artefactos e espaços culturais que lhes estão associados - que as comunidades, grupos e, eventualmente, indivíduos reconhecem como fazendo parte do seu património cultural. Este património cultural imaterial, transmitido de geração em geração, é constantemente recriado pelas comunidades e grupos em função do seu meio envolvente, da sua interação com a natureza e da sua história, e confere-lhes um sentido de identidade e de continuidade, contribuindo assim para promover o respeito da diversidade cultural e a criatividade humana. Para efeitos da presente Convenção, só será tomado em con- 
sideração o património cultural imaterial que seja compatível com os instrumentos internacionais relativos aos direitos humanos [...] (UNESCO, 2003, Artigo $2^{\circ}$ ).

Salienta-se a recriação do património por parte das comunidades, contrariando algumas visões do património como estático, imutável e completamente afastado da inovação.

Ao incluir os aspetos imateriais da vida das comunidades, na lista de património a que dá atenção, abre o caminho para políticas relativas ao seu reconhecimento e salvaguarda, alargando o que, tipicamente era abrangido pela legislação e, em muitos casos, validado pelas elites e pelas populações locais. Embora em Portugal a legislação relativa à Lei de Bases do Património (de 1985), contemplasse já um largo leque de visões, complementada ainda, com outra legislação, da qual se salienta a já referida RCM no 96 de 2000, o reconhecimento do património cultural imaterial, pela UNESCO, entendido como:

[...] as práticas, representações, expressões, conhecimentos e técnicas junto com os instrumentos, objetos, artefactos e lugares culturais que lhes são associados - que as comunidades, os grupos e, em alguns casos, os indivíduos reconhecem como parte integrante de seu património cultural [...] [património cultural imaterial] é transmitido de geração em geração e constantemente recriado pelas comunidades e grupos em função de seu ambiente, de sua interação com a natureza e de sua história, gerando um sentimento de identidade e continuidade, contribuindo assim para promover o respeito face à diversidade cultural e à criatividade humana (UNESCO, 2003).

Reitera, portanto, o caminho que havia começado a trilhar, anos antes. Importante, também, é, do nosso ponto de vista, o incentivo que este texto contém, para o reforço, já anteriormente enunciado, da multiculturalidade e da interculturalidade.

Assumidamente, como nos diz uma vez mais Arantes (2006), o património cultural não pode ser encarado como mera transmissão mecânica de conhecimento e práticas, de uma para outra geração. Esta transmissão implica escolhas, processos de seleção e hierarquização do conhecimento, portanto, não é neutra, mas antes um construto social, percetível para um grupo mais ou menos alargado e historicamente contextualizado.

Enquanto as instituições de governança locais tentam incentivar os territórios sob sua influência, pela aceitação e/ou promoção de ações de marketing e rótulos geradores de marcas locais que muitas vezes reforçam símbolos de identidade ou os (re)inventam, o estado central, assume a ideia de identidade portuguesa. De facto, no âmbito do reconhecimento da importância do património intangível, as práticas culinárias e a alimentação desempenham um papel deveras significativo, a que não serão porventura estranhos os impactos e consequências sociais, económicas e políticas que pode ter nos territórios. Senão, vejamos a RCM no 96 : 
Nas ações assim levadas a cabo no plano institucional, divulgando os valores tradicionais do receituário português, bem como os produtos agrícolas que nele se incorporam, tem sido privilegiada a diversidade regional enquanto fator decisivo de enriquecimento da gastronomia. Esta dimensão de cariz eminentemente económico vem assim acrescer à valia sociocultural que a gastronomia portuguesa representa. Crê-se, todavia, que este conjunto de ações já empreendidas devem passar a desenvolver-se de modo mais sistemático e consistente, presidindo-lhes um adequado enquadramento legal que clarifique o seu fundamento e objetivos e institua meios próprios de preservação e divulgação deste modo específico de expressão cultural, valorizando ainda o potencial económico que representa (RCM no 96, 2000).

A descoberta do património, segundo Peixoto (2002) traduz-se em operações de valorização simbólica que tem como objetivo, responder a uma situação de crise acentuada. Assumir que a criação do património não é apenas privilégio do passado, mas também do presente, portanto um produto da contemporaneidade, será fundamental. É neste contexto, que as culturas ditas tradicionais ou populares, emergem como recursos, cruzando a dimensão económica, e da cultura, mas também do emprego, com o objetivo de promover e alcançar o desenvolvimento integrado e sustentado. O património surge, portanto, como promotor do desenvolvimento local, conjugando a tradição e a inovação, isto é, as práticas tradicionais com novas formas de apresentação dos produtos, de divulgação, e mesmo de comercialização, mais adequadas aos novos gostos e exigências. Estas práticas, ainda que adaptadas e reconfiguradas, continuam a fazer parte de um imaginário coletivo (PEIXOTO, 2006), que as apropria.

A comida alentejana da pobreza, é novamente exemplo deste processo: quase considerado não comida, no passado, o almece ${ }^{3}$ ganha na atualidade, contornos de alimento altamente proteico, indicado em muitas dietas de emagrecimento e por razões estéticas. No polo oposto, em termos calóricos, os torresmos de rissol $^{4}$, consumidos em substituição da "carne boa", são servidos como petisco local (acontece em Serpa e Beja...) e considerados como iguaria; a conhecida banha com colorau ${ }^{5}$, que horroriza, sobretudo os fanáticos dos ginásios, ganha destaque em muitos restaurantes, servida como aperitivo, apresentada junto a pequenas taças cheias de azeites de diferentes qualidades, que se provam, molhando aí, o pão. Para uns, é uma viagem boa ou má, na memória; para outros, a oportunidade de experimentarem os sabores do passado - uma novidade ou a validação das memórias evocadas por quem comeu o que havia, agora elevado a produto regional ou local, com valor acrescentado.

Vejamos, a título de exemplo, alguns dos pratos do quotidiano dos oriundos e/ou residentes no Alentejo, que foram nossos informantes: 


\section{Quadro 1 - Pratos consumidos na infância (ditos tradicionais)}

\begin{tabular}{|c|c|c|c|}
\hline Informante & $\begin{array}{l}\text { Gé- } \\
\text { ne- } \\
\text { ro }\end{array}$ & $\begin{array}{l}\text { Naturali- } \\
\text { dade }\end{array}$ & $\begin{array}{l}\text { Pratos consumidos em casa (dos pais e } \\
\text { dos avós) }\end{array}$ \\
\hline 1(M.A.) & F & Serpa (vila) & $\begin{array}{l}\text { Favas de azeite, feijão com “catacuzes", } \\
\text { grão com acelga, grão de alho e louro, } \\
\text { caldo de ovos, caldo de toucinho, bor- } \\
\text { rego à pastora, caldo de cação, açordas, } \\
\text { masmaguias, caldos de beldroegas, papas, } \\
\text { vinagradas, lavadas, tomatadas, popias, } \\
\text { turtas, borrachos, arroz-doce, bolinho de } \\
\text { massa, peru estufado, castanhas e bolotas } \\
\text { cozidas com erva-doce, marmelos cozidos } \\
\text { com açúcar }\end{array}$ \\
\hline 2 (A.B.) & $\mathrm{F}$ & Pias & $\begin{array}{l}\text { Favas de Azeite, feijão com "catacuzes", } \\
\text { grão com acelga, cozido de grão, canja } \\
\text { com hortelã, borrego à pastora, caldo de } \\
\text { cação, açordas, sopa de beldroegas, papas, } \\
\text { vinagradas, lavadas, tomatadas, popias, } \\
\text { borrachos, fidalgos, arroz-doce, aletria } \\
\text { doce, bolinho de massa, entremeada, } \\
\text { entrecosto, mão de vaca, pezinhos de } \\
\text { borrego, pezinhos de porco, cabeça de } \\
\text { borrego assada }\end{array}$ \\
\hline 3 (B.E.) & $\mathrm{F}$ & Serpa & $\begin{array}{l}\text { Favas de azeite, feijão com "catacuzes", } \\
\text { grão com acelga, borrego à pastora, caldo } \\
\text { de cação, açordas, sopa de beldroegas, } \\
\text { tomatadas, popias, arroz-doce, bolinho de } \\
\text { massa, cozido de grão, feijão com abóbo- } \\
\text { ra, gaspacho, migas de espargos, espargos } \\
\text { com ovos, açorda de poejo, feijão com } \\
\text { tengarrinhas, abóbora assada }\end{array}$ \\
\hline 4 (M.C.A.) & $\mathrm{F}$ & Baleizão & $\begin{array}{l}\text { Feijão com carne de porco, açorda de ba- } \\
\text { calhau, caldo de pescada com espinafres, } \\
\text { caldo de tomate, caldo de bacalhau, feijão } \\
\text { com espinafres, ensopado de menina, per- } \\
\text { na de borrego acerejada, caldo de cação, } \\
\text { grão com acelga, grão com tengarrinhas, } \\
\text { cozido de couve, arroz-doce }\end{array}$ \\
\hline 5 (F.B.M.) & $\mathrm{M}$ & Beja & $\begin{array}{l}\text { Feijão com "catacuzes", grão com acel- } \\
\text { ga, cozido de grão, açorda de bacalhau, } \\
\text { caldo de pescada com espinafres, caldo } \\
\text { de tomate, caldo de bacalhau, feijão com } \\
\text { espinafres, feijão com tengarrinhas, vina- } \\
\text { gradas, gaspacho com peixe frito, entre- } \\
\text { meada, enchidos, cozido de grão, feijão } \\
\text { com abóbora, gaspacho, migas de espar- } \\
\text { gos, espargos com ovos, açorda de poejo, } \\
\text { açordas, migas, entrecosto, pezinhos de } \\
\text { borrego, pezinhos de porco, cabeça de } \\
\text { borrego assada }\end{array}$ \\
\hline
\end{tabular}




\begin{tabular}{|l|l|l|l|}
\hline 11 (J.O.) & M & $\begin{array}{l}\text { Serpa/ } \\
\text { Monte do } \\
\text { Peixoto }\end{array}$ & $\begin{array}{l}\text { Sopas de bacalhau, feijoada de cogumelos, } \\
\text { pescada ou bacalhau de azeite e vinagre, } \\
\text { sopas de peixe, ensopado de borrego, } \\
\text { açorda de bacalhau/pescada com poejos e } \\
\text { coentros, ovos com cogumelos, ovos com } \\
\text { espargos, grão com espinafres, gaspacho } \\
\text { acompanhado com azeitonas e rábano, } \\
\text { sopas de pão, feijões de azeite (sem carne), } \\
\text { migas de assobio, cachola, canja, tengarri- } \\
\text { nhas com feijão/grão, grãos de azeite, grão } \\
\text { com espinafres, feijão com espinafres, } \\
\text { feijão com couve, grãos com beldroegas, } \\
\text { sopas de peixe, sopa de beldroegas sem } \\
\text { queijo, açordas de ovos, galinha cozida } \\
\text { com batatas, galinha corada no forno, } \\
\text { chícharos, feijão com linguiça, cozido de } \\
\text { couve, beldroegas com feijão/grão, cozido } \\
\text { de borrego, catacuzes e acelgas com grão/ } \\
\text { feijão, filhós }\end{array}$ \\
\hline
\end{tabular}

Fonte: Autoria própria com base em trabalho de campo

É visível a pobreza, em termos de custos e de quantidade de proteína, desta alimentação. Os vegetais e leguminosas, bem como as plantas silvestres, ocupavam grande volume na dieta dos informantes. As "comidas de festa" abrangiam os doces, raramente consumidos, e as carnes e peixes "melhores", leia-se de primeira qualidade e peixes diferentes (para poucos).

Atualmente, o olival intensivo, o uso de pesticidas e a diminuição de solos de reserva agrícola nacional, constituem obstáculos à propagação de algumas das espécies vegetais selvagens, o que contribui para uma reconfiguração destas práticas alimentares e para a subida de preço de algumas destas espécies. São exemplos, o custo elevado dos espargos selvagens, das túbaras ${ }^{6}$ e das acelgas, bem como de ervas ditas de cheiro ou aromáticas (salsa, orégãos, poejo, coentros, hortelã da ribeira...).

Reforçamos a ideia de patrimonialização não ser alheia à de memória (construída, evocada e esquecida), como não o é relativamente à de identidade e/ou identidades. Diz-nos Maalouf (2003), que cada indivíduo é único e sendo-o, é possuidor de uma identidade que se compõe de múltiplas afiliações e pertenças. As questões da alimentação e dos sistemas culinários, ao cruzar tempos, espaços, sabores e interditos, cruzam os âmbitos das identidades individuais, culturais, sociais e coletivas, a ponto de ser difícil entender-se onde umas terminam e outras começam. Neste contexto, e porque pode entender-se o património como a materialização da identidade de um grupo ou de uma sociedade (SCHIELE 2002; PERALTA; ANICO, 2006), ele é também complexo e "contaminado" pelas identidades múltiplas que traduz. Como refere Ballart (1997, p. 17), o património surge quando "um indivíduo ou grupo de indivíduos identifica como seus, um objeto ou um conjunto de objetos". 
A definição de identidade não é única, dependendo, como todos os conceitos, de mundivisões e de contextos. Assim, pode entender-se como um processo de identificações, apropriadas historicamente, que conferem sentido ao grupo (CRUZ, 1993); como diferenciações em curso (SANTOS, 1993), construídas e reproduzidas pelo grupo; emergindo de processos interativos vivenciados na realidade quotidiana dos indivíduos, e, portanto, feita de trocas reais e simbólicas (MAALOUF, 1998) ou, ainda, contextualizadas e recontextualizadas ao longo do tempo de muito longa duração (GURVITCH, 1977), no âmbito de processos históricos, simbólicos e mitológicos, têm a capacidade de gerar diferentes tipos de sociedades (SANTOS, 1993), mas sempre "formada por processos sociais. Uma vez cristalizada, é mantida, modificada ou mesmo remodelada pelas relações sociais" (BERGER; LUCKMANN, 2010, p. 179). Certo é, como afirma Rodrigues (s.d.), que a identidade é construída através de sucessivas negociações, transformações e transitoriedades.

\section{OS PROCESSOS DE TURISTIFICAÇÃO NA ALIMENTAÇÃO}

A globalização está ligada a uma óbvia reafirmação de territórios e regiões como fóruns distintos de ação humana em relação às experiências alimentares, bem como à alimentação como património cultural e à alteridade, do ponto de vista turístico e do consumidor. Assim, todas as ações humanas permanecem de uma forma ou de outra regional e localmente contextualizadas.

A "patrimonialização alimentar" desempenha um papel extremamente importante na negociação de identidades passadas e presentes. Acontece em grandes centros cosmopolitas, mas principalmente em territórios portugueses periféricos, com características agrárias e população de baixa densidade, como a região do Baixo Alentejo. Assume alta importância quanto à integração dos grupos sociais na economia global e na atribuição de valor às pessoas e substâncias envolvidas nesse processo.

As questões económicas e o seu impacto no desenvolvimento dos territórios, sobretudo mais despovoados e envelhecidos, alguns dos quais se voltam para a atividade turística e valorização dos produtos regionais, é contemplada em várias alíneas da mesma RCM, que propõem uma ação concreta:

[...] d) A criação de condições que permitam a inventariação dos estabelecimentos de restauração e de bebidas existentes no País que incluam nas suas ementas receitas da cozinha tradicional portuguesa; e) A promoção interna e externa da gastronomia nacional, designadamente com o objetivo de fomentar a procura turística; f) A criação de concursos locais, regionais e nacionais de gastronomia; g) A promoção de novas receitas confecionadas com produtos genuinamente portugueses; h) A contribuição para a melhoria da oferta turística nacional [...] (RCM n ${ }^{\circ}$ 96, 2000). 
Como Tamaso (2002) refere, nas últimas décadas, tem vindo a observar-se uma contínua e crescente obsessão com o passado e com as raízes e, sobretudo, com o que habitualmente se designa por património (LOWENTHAL, 1998a, 1998b). Esta moda configura uma procura dos lugares típicos - restaurantes, bares, tabernas, cafés - que desde a decoração à ementa, se reinventam no "rústico", "típico", "regional", "neo- qualquer coisa", fornecendo a comida de conforto "autêntica" ou "reinventada", "conceptual", mais abundantes nas zonas do interior. O presente ano de 2020, a que a pandemia não é alheia, impossibilitou ou pelo menos inibiu, muitos portugueses que tinham as suas férias programadas para o estrangeiro, de atravessar fronteiras. Portanto, o turismo nacional em terras lusas acompanhou a fuga do litoral para o interior, dos grandes para os pequenos centros, onde, uma vez mais, se valorizou o típico e o tradicional.

Juntam-se, como nos diz o texto da RMC, aos pratos típicos, os concursos promovidos por autarquias, associações de comerciantes etc., os festivais, as rotas... O reconhecimento da Dieta Mediterrânica como Património Cultural Imaterial pela UNESCO, juntamente com a promoção de diversas "rotas" de património gastronómico, são evidências claras dessas tendências em território português:

Entre este conjunto de ações contam-se centenas de eventos promovidos anualmente no País, por iniciativa das mais diversas entidades, frequentemente integrados em importantes celebrações, que constituem sempre verdadeiro polo de atração para turistas, nacionais e estrangeiros. De resto, tem sido a reconhecida componente de atração turística da gastronomia nacional e o esforço de todos no sentido da preservação da sua autenticidade que têm proporcionado o desenvolvimento contínuo do sector da restauração, de crucial importância económica global em Portugal, e com especiais efeitos no desenvolvimento do sector agrícola, designadamente no que se refere à exigência de produtos de superior qualidade (RCM no 96, 2000).

Como consequência, as culturas alimentares mudaram-se para o centro de uma triangulação entre cultura, identidade e mercados e são, na verdade, consideradas uma das "marcas de identidade" portuguesas.

Pessoas de diferentes comunidades têm uma relação diferente com a comida e, portanto, as suas escolhas alimentares são influenciadas tanto pela sua formação socioeconómica, como cultural. As viagens transfronteiriças e a circulação cultural, moldam as formas pelas quais indivíduos e grupos acomodam e reinventam a relação entre passado e presente. Também as instituições e atores supranacionais e intergovernamentais desempenham um papel cada vez mais importante na interação entre públicos ou consumidores e políticas, acrescentando valor, despendendo verbas, portanto alocando capital e transformando os valores culturais que envolvem patrimónios específicos, como é o caso do alimentar. A comida e a culinária podem permitir problematizar a 
noção de grupos "étnicos", bem como uma dimensão exótica do "outro", quando as fronteiras se atravessam, mas permite igualmente, encontrar o exotismo "dentro de casa", por via dos fenómenos de globalização (pizza), de moda (sushi), de proximidade geográfica (tapas) ou da tradição (tengarrinhas com feijão branco ${ }^{7}$; pés de porco ou chispe, orelha de porco, pezinhos de borrego; cabeça de borrego assada... ${ }^{8}$ ).

Uma aspiração por experiências diferentes ou exóticas relacionadas com o turismo, alimentação ou paisagens, define como a economia regional funciona atualmente. De facto, os consumidores desejam - e estão dispostos a pagar - experiências significativas que possam compartilhar com os outros. Uma cozinha inovadora e comercial que olha para o passado, reinventando tradições para um caminho a seguir, emerge em muitos locais de Portugal, não sendo o Baixo Alentejo, uma exceção. E uma cozinha tradicional pouco conotada com as elites e os mais ricos, que encontravam refúgio na cozinha internacional, sobretudo francesa, emerge. Saber cozinhar, ser-se conhecedor dos ingredientes exóticos e de outras paragens, mas também os selvagens, menorizados e autóctones, é, de repente, desejado, desejável e bem visto - a este fenómeno, não são alheios os muitos, quase incontáveis, programas e concursos de culinária, que passam tanto nos canais nacionais como nos de cabo. Junte-se as redes sociais, os "posts" sobre comida, as fotos, os vídeos que ensinam todos os truques possíveis e imaginários, o aparecimento de formação de nível médio e superior, para profissionais da restauração, e o resultado é a existência de Chefs, cozinheiros e cozinheiros amadores.

A comida, de repente, tornou-se uma moda e, no caso português, a comida da pobreza transforma-se em comida de elite. Em muitos dos restaurantes onde os turistas e os clientes em geral "não comem", fazem antes, degustações, a intenção não é matar a fome, mas suscitar uma experiência com base na cozinha tradicional reinventada e desconstruída - a cozinha conceptual e a cozinha de autor. Longe, muito longe, está a experiência da travessa cheia, da comida que, se não sobra, é de miséria. Num e noutro caso, a cozinha que se experiencia, afasta-se da caseira. Pode considerar-se a emergência, a par dos restaurantes, de "territórios dos sentidos", uma nova categoria de lugares onde se serve comida que não se partilha, não se troca, é explicada e sem dúvida tem uma dimensão artística - é arte comestível, ensaiada, experimentada e rigorosamente controlada.

Obviamente, a maioria dos restaurantes nos concelhos de Beja e Serpa e fora deles, oferecem a comida de conforto - a que permite provar e petiscar o que cada um, à mesa, pede. As maneiras, boas ou más, a etiqueta, a comensalidade que define graus de confiança e intimidade expressa-se nesta partilha - de comida, de conversa, de símbolos, que convergem numa identidade e património comuns.

Ocasionalmente, as atitudes que alguns proprietários de restaurantes, menos honestos, têm quanto à comida que servem - em termos de 
qualidade mas também no que concerne a modos de confeção (sobretudo em Lisboa), desvirtua o que se pretende com a RCM:

$\mathrm{O}$ reconhecimento de um tal valor às artes culinárias cria responsabilidades acrescidas no que respeita à defesa da sua autenticidade, bem como à sua valorização e divulgação, tanto no plano interno quanto internacionalmente (RCM no 96, 2000).

Os turistas procuram comida tradicional, "típica” dos lugares, mas falta-lhes o conhecimento dos sabores, odores e texturas, para poderem ser exigentes. Frequentemente, não conhecem os pratos que consomem e não estão cientes do que lhes deve ser servido para degustar. A falta do domínio de uma "gramática do gosto" torna possível o embuste e a criação de uma falsa memória dos sabores. A ganância e a ausência da compreensão da importância da autenticidade e dos processos tradicionais, obviamente com a margem que sempre existe para o toque pessoal, pode transformar o património culinário, numa grande mentira - felizmente, esses casos não são muito comuns. E como consequência desses atos, a intenção inicial de preservação do património, transforma-se em degradação.

Exemplos dessa atitude em relação à "tradição" é a proliferação em locais turísticos portugueses, de restaurantes que afirmam servir comida tradicional, mas dão aos turistas uma (má) reinvenção de receitas: sardinhas com batatas fritas ${ }^{9}$ (observada durante o trabalho de campo em Lisboa, 2018); arroz-doce ${ }^{10}$ feito com pudim pré-preparado, em vez de ovos e leite, porque é mais doce e os turistas norte-americanos preferem (observado durante o trabalho de campo em Lisboa, 2017); migas e açordas (receitas tradicionais da culinária portuguesa feitas com tradicional pão de cereal de trigo, água, alho, azeite ou gordura de porco, sal e ervas) feitas com outros tipos de pão, adicionando temperos exóticos e mudando a consistência da massa da açorda, bem como o sabor (observado durante o trabalho de campo em Beja, 2016). É tudo, exceto o que se pretende:

Neste sentido, tem vindo a ser desenvolvido há já alguns anos um conjunto de ações visando inventariar, valorizar, promover e salvaguardar o receituário português, com o objetivo primeiro de garantir o seu caracter genuíno e, bem assim, de promover o seu conhecimento e fruição, por forma, ainda, a que se transmita às gerações vindouras ( $\mathrm{RCM} \mathrm{n}{ }^{\circ} 96$, 2000).

\section{CONSIDERAÇÕES FINAIS}

A patrimonialização, como processo de negociação e como olhar de narrativas, vozes, memórias, afetos e emoções, envolvidas na construção do património, expressa uma dimensão política e uma representação comunitária. A investigação mostra como as cozinhas nacionais são criadas ou inventadas e também mostram como a globalização pode reforçar a identidade local. 
Os sistemas alimentares estão engajados em comunidades, famílias, territórios e países, além de fronteiras culturais e tornaram-se transculturais. As práticas culinárias existem num tempo de longa duração, adaptando-se e sendo reinventadas em função de momentos de abundância ou escassez.

A repressão religiosa e política, a pobreza, as catástrofes, podem ser aspetos inerentes às transformações nos sistemas alimentares e com forte impacto na vida comum. No entanto, as práticas de consumo, bem como as formas de confeção dos alimentos, tendem a ser mantidas. Essas dimensões são, ao mesmo tempo, património cultural, declarações políticas e formas de resistência, apesar das imposições locais ou dos processos de turistificação.

A vaga universalizante da UNESCO, torna-se cada vez mais, um valor para os territórios que agora percebem que ser-se moderno, é ser antigo, configurando modelos de desenvolvimento ancorados no património (TAMASO, 2002). Com efeito, propicia o desenvolvimento económico, ao atrair o turismo cultural (CHOAY, 2001), resultado do reconhecimento e valorização do património "dos outros", em linha com as propostas da entidade.

\section{NOTAS}

1. United Nations Educational, Scientific and Cultural Organization.

2. Movimento Internacional para a Nova Museologia.

3. O soro coalhado, que sai do "requeijão", quando a massa é colocada num pano e calcada (depois o pano é torcido para compactar melhor a massa que forma o requeijão). É um líquido altamente proteico que se bebe simples ou com sal e pimenta. Pode ser usado como base para sopas de pão.

4. Redanho de porco frito com sal

5. Banha de porco à qual se adiciona colorau em pó. Usa-se (usava-se como comida de pobreza) para barrar o pão, em substituição da manteiga.

6. Uma espécie de cogumelos selvagens abundantes no Baixo Alentejo.

7. Tengarrinhas são cardos rasteiros muito usados na comida da pobreza. São plantas selvagens que exigem muito trabalho de preparação. Eram ripadas, para as livrar dos picos e escaldadas com água a ferver antes de serem cozinhadas. Escaldavam-se para não deixarem o caldo negro e tinham um paladar semelhante a alcachofras. Os caules eram cortados aos pedacinhos e cozidos com feijão.

8. Considerados como carne de segunda categoria, tal como os miúdos (órgãos internos) dos porcos, borregos e vacas.

9. As sardinhas assadas (como estavam a ser consumidas por aqueles turistas) são servidas com batatas cozidas e salada de tomate, alface e cebola. A salada também pode conter pimentos assados, verdes e vermelhos. É temperada com sal, azeite e vinagre. Em substituição das batatas (forma mais ancestral do prato) ou complementarmente podem ser servidas com fatias de pão dito de cabeça, alentejano, de mafra etc. Nunca deve ser um pão industrial, de farinha muito fina. Na zona Norte e centro de Portugal, usa-se comer sardinhas tam- 
bém com broa (pão de milho) e pão de centeio ou de mistura (farinha de trigo e de centeio).

10. O arroz-doce, é um prato feito de arroz aberto em pouca água fervente, cozido em leite e açúcar, temperado com casca de limão e canela em pau. Em receitas conventuais e das elites podia também levar água de flor de laranja, cravinho da índia e açafrão. Depois de empratado é polvilhado com canela em pó. $\mathrm{O}$ arroz doce, dependendo das regiões do país leva ovos ou não. Por esta razão, pode ter a cor amarela (dos ovos), dourada (do açafrão, variante caída em desuso) ou branca.

\section{REFERÊNCIAS}

ARANTES, António. Diversity, heritage and cultural politics. Theory, Culture \& Society, v. 7-8, n. 24, p. 290-296, 2006. Disponível em: $<$ http://tcs.sagepub.com>. Acesso em: 06 mai. 2007.

AUGÉ, Marc. Não-Lugares: introdução a uma antropologia da supermodernidade. São Paulo: Papirus, 1994.

BALLART, Josep. El patrimonio histórico y arqueológico: valor y uso. Barcelona: Ariel, 1997.

BERGER, Peter; LUCKMANN, Thomas. A construção social da realidade. Lisboa: Dinalivro, 2010.

CANESQUI, Ana Maria. Comida de rico, comida de pobre: um estudo sobre a alimentação num bairro popular. Tese (Doutorado) - Faculdade de Ciências Médicas, Unicamp, Campinas, 1976.

CANESQUI, Ana Maria; GARCIA, Rosa Wanda (org.). Antropologia e nutrição: um diálogo possível. Rio de Janeiro: Editora FIOCRUZ, 2005. Disponível em: <http://books.scielo.org>. Acesso em: $28 \mathrm{fev}$. 2014.

CHOAY, Françoise. A Alegoria do Patrimônio. São Paulo: Estação Liberdade/Unesp, 1992.

CRUZ, Rodrigo Díaz. Experiencias de la Identidad. Revista Internacional de Filosofía Política, n. 2, p. 63-74, 1993.

DAMATTA, Roberto. Sobre o simbolismo da comida no Brasil. Correio da Unesco, v. 15, n. 7, p. 21-23, 1987.

D’ENCARNAÇÃO, José. Cidade, gastronomia e património. Revista Memória em Rede, v. 2, n. 7, p.1-12, 2012.

GURVITCH, Georges. Tratado de sociologia I. São Paulo: Martins Fontes, 1997.

HALBWACHS, Maurice. On collective memory. Chicago: University Chicago Press, 1992.

HJALAGER, Anne-Meet; RICHARDS, Greg. Tourism and gastronomy. New York: Routledge, 2002.

LOWENTHAL, David. El pasado es um país extraño. Madrid: Ediciones Akal, 1998a.

LOWENTHAL, David. The heritage cruzade and the spoils of history. Cambridge: Cambridge University Press, 1998b.

MAALOUF, Amin. Les identités meurtrières. Paris: Bernard Grasset, 1998. 
MAALOUF, Amin. In the name of identity. London: Penguin Books, 2003.

PÉREZ, Xerardo. Patrimonialização e transformação das identidades culturais. In PORTELA, J.; CASTRO CALDAS, J. (org.). Portugal chão. Oeiras: Celta, 2003. p. 231-247.

PEIXOTO, Paulo. Os meios rurais e a descoberta do património. Oficina do Centro de Estudos Sociais, n. 175, 2002.

PEIXOTO, Paulo. O Douro a todo o vapor: alegorias do turismo rural. In: ALMEIDA, Joaquim Anécio; SOUZA, Marcelino de. (org.). Turismo rural: patrimônio, cultura e legislação. Santa Maria: Facos, 2006. p. 121-135.

PERALTA, Elsa. Património e identidade: os desafios do turismo cultural. Antropológicas, n. 4, p. 217-224, 2000.

PERALTA, Elsa; ANICO, Marta (org.). Patrimónios e identidades: ficções contemporâneas. Oeiras: Celta, 2006.

PRATS, Llorenç. Antropología y patrimonio. Barcelona: Ariel, 1997.

QUITÉRIO, José. Comer em português. Lisboa: CTT, 1997.

RCM no 96/2000. Diário da República, n. ${ }^{\circ}$ 171/2000, Série I-B, 26 jul. 2000. Disponível em: <https://data.dre.pt/eli/resolcons$\mathrm{min} / 96 / 2000 / 07 / 26 / \mathrm{p} / \mathrm{dre} / \mathrm{pt} / \mathrm{html}>$. Acesso em: 05 abr. 2018.

RICOLFE, José Serafín; MERINO, Bernat Roig; MARZO, Sara Valencia; FERRANDIS, Ma Rabadán; RODRÍGUEZ, Cristina Martínez. Actitud hacia la gastronomía local de los turistas: dimensiones y segmentación de mercado. Pasos-Revista de Turismo y Património Cultural, v. 6, n. 2, p. 189-198, 2008. Disponível em: <www.pasosonline.org>. Acesso em: 25 jan. 2018.

RODRIGUES, Donizette. Património cultural, memória social e identidade: uma abordagem antropológica. s.d. Disponível em: $<$ https:// www.academia.edu/16487357/CS3_rodrigues_donizete_patrimonio_cultural_memoria_social_identidade_uma_abordagem_antropologica>. Acesso em: 17 dez. 2018.

SANTOS, Boaventura de Sousa. Modernidade, identidade e a cultura de fronteira. Tempo Social - Rev. Sociol. USP, v. 5, p. 1-2, p. 31-52, 1993.

SCHIELE, Bernard. Patrimoines et identités. Québec: Éditions MultiMondes, 2002.

SCHLUTER, Regina. Gastronomia e turismo. São Paulo: Aleph, 2006 a.

SCHLUTER, Regina. Turismo y patrimonio gastronómico: una perspectiva. Buenos Aires: Centro de Investigaciones y Estudios Turísticos, 2006b.

SOBRAL, José Manuel. Nacionalismo, Culinária e Classe. Ruris: revista do Centro de Estudos Rurais, v. 1, n. 2, p. 13-51, set. 2007.

SUTTON, David. Remembrance of repasts: an anthropology of food and memory. Oxford: Berg, 2001.

TAMASO, Izabela. Património imaterial: velhos, objetos, novos desafios. In: REUNIÃO DA SOCIEDADE BRASILEIRA PARA O PRO- 
GRESSO DA CIÊNCIA (SBPC), 54, 2002, Goiânia. Resumos [CD-ROM]. Goiânia: Sociedade Brasileira para o Progresso da Ciência, 2002.

UNESCO. Convenção para a salvaguarda do património cultural imaterial. Paris: 2003. Disponível em: <https://ich.unesco.org/doc/src/ 00009-PT-Portugal-PDF.pdf > . Acesso em: 04 jul. 2008.

UNESCO. Expert meeting on community involvement in safeguarding intangible cultural heritage: towards the implementation of 2003 Convention. Tokio, Japan 13-15 March 2006. Disponível em: <http:// www.unesco.org/culture/ich>. Acesso em: 05 jul. 2008.

\section{Fontes Orais:}

J.O. [Homem, 69 anos]. Depoimento [2015; 2016; 2017]. Entrevistador: Ana Felisbela de Albuquerque Piedade. Beja: 2015, 2016, 2017.

M.V.C. [Mulher, 83 anos]. Depoimento [2012; 2013; 2017]. Entrevistador: Ana Felisbela de Albuquerque Piedade. Beja: 2012, 2013, 2017.

G.S. [Mulher, 79 anos]. Depoimento [2018]. Entrevistador: Ana Felisbela de Albuquerque Piedade. Barreiro: 2018.

C.G. [Homem, 49 anos]. Depoimento [2019]. Entrevistador: Ana Felisbela de Albuquerque Piedade. Beja: 2019.

SUBMETIDO EM: 15/12/2020

APROVADO EM: 21/04/2021 